\section{Botulinum toxin treatment for acute traumatic complete sixth nerve palsy}

H-L Hung, L-Y Kao and M-H Sun

\begin{abstract}
Aims To investigate the benefits of botulinum toxin (BTX) injection for acute unilateral complete sixth nerve palsy caused by trauma.

Methods We retrospectively reviewed patients treated for acute unilateral complete sixth nerve palsy caused by head injury during a 10-year period (between March 1993 and February 2003) in our hospital. The BTX treatment group was defined as patients who received BTX injection within 3 months of injury. Patients who presented within 3 months of trauma, and had no previous BTX injection or surgery were enrolled as the conservative treatment group. Comparison of the patient demographics, palsy characteristics, angle of deviations, and recovery rates were made between the two groups.
\end{abstract}

Results In all, 33 patients were enrolled by our inclusion criteria. Of these, 19 patients were treated conservatively, and 14 patients were treated with BTX. A total of $79 \%$ of our patients presented with abduction deficit of grade -5 . The results showed that there was no significant difference in the outcome for the two groups based on age, gender, time to presentation, severity, and initial angle of deviation. The BTX group had a higher recovery rate than the conservative treatment group (64.3 vs $26.3 \%$,

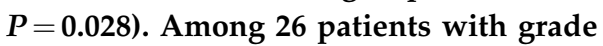
-5 abduction deficit, the recovery rate was higher in the BTX-treated patients than in the conservatively treated patients, which

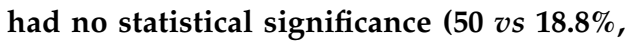
$P=0.09$ ).

Conclusion BTX facilitates recovery of acute traumatic complete sixth nerve palsy in severely injured patients.

Eye (2005) 19, 337-341. doi:10.1038/sj.eye.6701460 Published online 23 July 2004
Keywords: botulinum toxin; trauma; sixth nerve palsy

\section{Introduction}

The injection of botulinum toxin (BTX) into the ipsilateral medial rectus muscle has been advocated in the management of lateral rectus paresis or palsy since the mid-1980s. Scott and $\mathrm{Kraft}^{1}$ postulated that BTX reduces contracture of the medial rectus muscle, and allows for more complete recovery of lateral rectus muscle function. Several other studies have since tried to clarify how BTX affects the recovery of lateral rectus palsy. However, there is no agreement about the effect of BTX among these studies. Some authors believe that early BTX injection can facilitate the recovery of acute sixth nerve palsy, ${ }^{2-5}$ but others do not. ${ }^{6-8}$ Several factors can cause such discrepancy. One is the diversity of a aetiology among these studies. As we know, sixth nerve palsies caused by different aetiology have different prognoses. Most studies enrolled several types of aetiology at the same time, which could make the results confusing. The severity of palsy and the laterality are also important factors affecting final prognosis. ${ }^{9}$ Patients with complete and bilateral palsy seem to have less chance of recovery. However, previous studies seldom confine their results to a specific grade of severity. In addition, there was no universal definition for 'recovery' of a sixth nerve palsy in these previous studies. It is difficult, then, to compare the recovery rate between studies that had different definitions. All the factors mentioned above would influence the outcome of studies on BTX treatment in sixth nerve palsy.

In this study, we enrolled patients affected by acute unilateral sixth nerve palsy with a single aetiology (trauma) and the most severe grades ( -4 to -5 abduction deficit). We also used strict criteria to define recovery. All the BTX treatment
Division of Neuroophthalmology Department of Ophthalmology Chang Gung Memorial Hospital Taipei, Taiwan

Correspondence: H-L Hung Division of Neuroophthalmology Department of Ophthalmology Chang Gung Memorial Hospital 5, Fu-Hsing Street Kweishan

Taoyuan, Taiwan.

Tel: +88633281200 ext.8666

Fax: + 88633287798

E-mail: lisahung@ adm.cgmh.org.tw

Received: 1 October 2003 Accepted: 12 January 2004 Published online: 23 July 2004 
was performed within 3 months of onset of sixth nerve palsy, and the results were compared with the conservative treatment group to evaluate the effect of BTX.

\section{Methods}

This was a retrospective study. All the patients treated in our hospital during a 10-year period (between March 1993 and February 2003) for acute sixth nerve palsy caused by trauma were reviewed. Data, including age, gender, date of trauma, severity and forms of trauma, systemic condition, degree of abduction deficit, and angle of deviation were collected by chart review. Abduction deficit was graded using the scale described by Scott and Kraft: 0 (normal), -1 (can rotate eye from midline to $75 \%$ of full rotation), -2 (to $50 \%$ of full rotation), -3 (to $25 \%$ of full rotation), -4 (to midline), and -5 (inability to rotate to midline). ${ }^{1}$ A complete palsy was defined as -4 or -5 abduction deficit. Angle of deviation was measured in prism diopters (PD) by simultaneous prism and cover test in the primary position at a distance of $6 \mathrm{~m}$.

Nonparametric data were carried out using the Mann-Whitney $U$-test. Discrete variables were analysed by the Fisher exact test. A $P$-value less than 0.05 was considered significant in all analyses.

Inclusion criteria were as follow: (1) initial examination within 3 months of trauma; (2) history of head injury; (3) no other systemic conditions that could cause sixth nerve palsy (diabetes mellitus, hypertension, cerebrovascular disease, tumours, etc); (4) inability to abduct one eye (bilateral cases were excluded); (5) abduction deficit of -4 or -5 ; (6) diplopia in the primary position; (7) visual acuity $\geqslant 6 / 60$ in each eye; (8) distance esotropia $\geqslant 10 \mathrm{PD}$; and (9) no previous treatment with BTX or surgery. The BTX group was defined as patients who received BTX injection at the medial rectus muscle within 3 months of injury. The conservative treatment group was defined as patients who had not received any BTX injection or surgery within 6 months of injury.

Follow-up data regarding diplopia, abduction deficit, and angle of deviation were collected at intervals of 2 weeks, 1, 3, and 6 months after injury. For those patients who received multiple injections, additional data were collected at 1 and 3 months after the last injection. Recovery was defined as the absence of diplopia in the primary position, and a distance esotropia of less than $10 \mathrm{PD}$ in the primary position at 6 months after injury. The time for assessment of outcome in patients who received multiple injections was also be at least 3 months after the last injection to ensure the correct assessment of recovery. Of the 35 initially eligible patients, two nonresolved patients receiving conservative treatment had less than 6 months of follow-up and were excluded.

\section{Results}

In all 33 patients with complete follow-up were enrolled. Of these, 14 had BTX injection within 3 months of injury and were defined as the BTX group (Table 1). For the BTX-treated patients, the ages ranged from 19 to 59 years (median 44 years). Nine were male and five were female. Intervals of injury to the first presentation ranged from 4 to 63 days (median 22 days). Four patients had an abduction deficit of grade -4 and $10(71.4 \%)$ had grade -5 . Initial angle of deviation ranged from 16 to $60 \mathrm{PD}$

Table 1 The BTX group

\begin{tabular}{|c|c|c|c|c|c|c|c|c|c|c|}
\hline \multirow{2}{*}{$\begin{array}{l}\text { Patient } \\
\text { no. }\end{array}$} & \multirow{2}{*}{$\begin{array}{c}\text { Age } \\
\text { (years) }\end{array}$} & \multirow[t]{2}{*}{ Sex } & \multirow{2}{*}{$\begin{array}{l}\text { Interval from } \\
\text { onset (weeks) }\end{array}$} & \multicolumn{2}{|c|}{ Preinjection data } & \multirow[t]{2}{*}{ Injections } & \multicolumn{3}{|c|}{6 months } & \multirow[t]{2}{*}{ Recovery } \\
\hline & & & & $\begin{array}{c}\text { Abduction } \\
\text { deficit }\end{array}$ & $\begin{array}{c}\text { Angle of } \\
\text { deviation }(P D)\end{array}$ & & $\begin{array}{c}\text { Abduction } \\
\text { deficit }\end{array}$ & $\begin{array}{c}\text { Angle of } \\
\text { deviation }(P D)\end{array}$ & $\begin{array}{c}\text { Fusion in } \\
\text { primary position }\end{array}$ & \\
\hline 1 & 56 & $\mathrm{M}$ & 4 & -5 & 30 & 2 & 0 & 0 & $\mathrm{Y}$ & $\mathrm{Y}$ \\
\hline 2 & 36 & M & 9 & -5 & 58 & $3^{a}$ & -4 & 40 & $\mathrm{~N}$ & $\mathrm{~N}$ \\
\hline 3 & 45 & $\mathrm{M}$ & 1 & -4 & 50 & $3^{a}$ & -1 & 8 & $\mathrm{Y}$ & $\mathrm{Y}$ \\
\hline 4 & 23 & $\mathrm{M}$ & 3 & -5 & 35 & 1 & -5 & 35 & $\mathrm{~N}$ & $\mathrm{~N}$ \\
\hline 5 & 58 & $\mathrm{~F}$ & 0.5 & -4 & 40 & 1 & 0 & 0 & $\mathrm{Y}$ & $\mathrm{Y}$ \\
\hline 6 & 47 & $\mathrm{~F}$ & 0.5 & -5 & 60 & $4^{a}$ & -2 & 0 & $\mathrm{Y}$ & $\mathrm{Y}$ \\
\hline 7 & 19 & $\mathrm{~F}$ & 2 & -5 & 30 & 1 & -1 & 6 & $\mathrm{Y}$ & $\mathrm{Y}$ \\
\hline 8 & 53 & $\mathrm{M}$ & 4 & -5 & 55 & 1 & -5 & 30 & $\mathrm{~N}$ & $\mathrm{~N}$ \\
\hline 9 & 59 & $\mathrm{M}$ & 1 & -4 & 35 & 1 & 0 & 0 & $\mathrm{Y}$ & $\mathrm{Y}$ \\
\hline 10 & 35 & $\mathrm{M}$ & 3 & -5 & 40 & 1 & -2 & 14 & $\mathrm{~N}$ & $\mathrm{~N}$ \\
\hline 13 & 44 & $\mathrm{M}$ & 6 & -5 & 23 & 1 & -2 & 0 & $\mathrm{Y}$ & $\mathrm{Y}$ \\
\hline 14 & 25 & $\mathrm{M}$ & 3 & -5 & 16 & 1 & -4 & 18 & $\mathrm{~N}$ & $\mathrm{~N}$ \\
\hline
\end{tabular}

$\mathrm{PD}=$ prism diopters.

${ }^{\text {a } T h r e e ~ p a t i e n t s ~ r e c e i v i n g ~ m u l t i p l e ~ i n j e c t i o n s ~ w e r e ~ a s s e s s e d ~ f o r ~ o u t c o m e ~ l a t e r ~ t h a n ~} 6$ months. 
Table 2 Conservatively treated group

\begin{tabular}{|c|c|c|c|c|c|c|c|c|c|}
\hline \multirow[t]{2}{*}{ Patient no. } & \multirow[t]{2}{*}{ Sex } & \multirow{2}{*}{$\begin{array}{l}\text { Age } \\
\text { (years) }\end{array}$} & \multirow{2}{*}{$\begin{array}{l}\text { Interval from } \\
\text { onset (weeks) }\end{array}$} & \multicolumn{2}{|c|}{ First visit } & \multicolumn{3}{|c|}{6 months } & \multirow[t]{2}{*}{ Recovery } \\
\hline & & & & $\begin{array}{l}\text { Abduction } \\
\text { deficit }\end{array}$ & $\begin{array}{c}\text { Angle of } \\
\text { deviation (PD) }\end{array}$ & $\begin{array}{l}\text { Abduction } \\
\text { deficit }\end{array}$ & $\begin{array}{c}\text { Angle of } \\
\text { deviation (PD) }\end{array}$ & $\begin{array}{c}\text { Fusion in } \\
\text { primary position }\end{array}$ & \\
\hline 15 & M & 35 & 4 & -4 & 30 & 0 & 0 & $\mathrm{Y}$ & Y \\
\hline 16 & $\mathrm{M}$ & 47 & 5 & -5 & 40 & -2 & 30 & $\mathrm{~N}$ & $\mathrm{~N}$ \\
\hline 17 & $\mathrm{M}$ & 42 & 1 & -5 & 30 & -5 & 40 & $\mathrm{~N}$ & $\mathrm{~N}$ \\
\hline 18 & $\mathrm{M}$ & 47 & 3 & -4 & 25 & -2 & 8 & Y & Y \\
\hline 19 & M & 12 & 0.5 & -5 & 30 & -1 & 5 & $\mathrm{Y}$ & $\mathrm{Y}$ \\
\hline 20 & M & 3 & 4 & -4 & 20 & -3 & 35 & $\mathrm{~N}$ & $\mathrm{~N}$ \\
\hline 21 & M & 16 & 6 & -5 & 20 & -5 & 60 & $\mathrm{~N}$ & $\mathrm{~N}$ \\
\hline 22 & M & 29 & 0.5 & -5 & 30 & -1 & 15 & $\mathrm{~N}$ & $\mathrm{~N}$ \\
\hline 23 & M & 46 & 2 & -5 & 30 & -5 & 50 & $\mathrm{~N}$ & $\mathrm{~N}$ \\
\hline 24 & M & 59 & 4 & -5 & 50 & -5 & 50 & $\mathrm{~N}$ & $\mathrm{~N}$ \\
\hline 25 & M & 39 & 6 & -5 & 30 & -2 & 16 & $\mathrm{~N}$ & $\mathrm{~N}$ \\
\hline 26 & M & 9 & 0.5 & -5 & 30 & 0 & 0 & $\mathrm{Y}$ & Y \\
\hline 27 & $\mathrm{~F}$ & 64 & 4 & -5 & 40 & -5 & 50 & $\mathrm{~N}$ & $\mathrm{~N}$ \\
\hline 28 & $\mathrm{~F}$ & 23 & 0.5 & -5 & 60 & -5 & 60 & $\mathrm{~N}$ & $\mathrm{~N}$ \\
\hline 29 & $\mathrm{~F}$ & 52 & 6 & -5 & 60 & -5 & 60 & $\mathrm{~N}$ & $\mathrm{~N}$ \\
\hline 30 & $\mathrm{~F}$ & 35 & 1 & -5 & 20 & -1 & 0 & $\mathrm{Y}$ & $\mathrm{Y}$ \\
\hline 31 & $\mathrm{~F}$ & 16 & 2 & -5 & 20 & -5 & 90 & $\mathrm{~N}$ & $\mathrm{~N}$ \\
\hline 32 & $\mathrm{~F}$ & 36 & 12 & -5 & 30 & -5 & 55 & $\mathrm{~N}$ & $\mathrm{~N}$ \\
\hline 33 & $\mathrm{~F}$ & 36 & 0.5 & -5 & 30 & 0 & 30 & $\mathrm{~N}$ & $\mathrm{~N}$ \\
\hline
\end{tabular}

$\mathrm{PD}=$ prism diopters.

(mean 36.7 PD). The dose of BTX ranged from 5 to $10 \mathrm{U}$ per injection. Of the 14 patients, nine received a single injection; two received two injections, two received three injections, and one received four injections. The angle of deviation at the final follow-up ranged from 0 to 8 PD in the recovered patients (mean 2.2 PD) and 14 to $40 \mathrm{PD}$ in the nonrecovered (mean 27.4PD). The recovery rate in the BTX group was $64.3 \%$.

For the 19 conservatively treated patients (Table 2 ), the ages ranged from 3 to 64 years (median 36 years). Of these, 12 were male and seven were female. Intervals of injury to first presentation ranged from 3 to 84 days (median 23 days). Three patients had an abduction deficit of grade -4 and $16(84.2 \%)$ had grade -5 . Initial angle of deviation ranged from 20 to $60 \mathrm{PD}$ (mean $32.9 \mathrm{PD}$ ). The angle of deviation at the final follow-up ranged from 0 to $8 \mathrm{PD}$ in the recovered patients (mean 2.6 PD) and 15 to $90 \mathrm{PD}$ in the nonrecovered (mean 45.7 PD). The recovery rate in the conservative treatment group was $26.3 \%$.

There was no significant difference in the outcome for the two groups based on age, gender, time to presentation, severity, and initial angle of deviation. The recovery rate in the BTX group was significantly higher than the conservative group $(P=0.028)$. Also, the final angle of deviations of nonrecovered patients in the conservative group was larger than the deviations in the BTX group $(P=0.032)$.

To determine whether the severity of the palsy influenced the benefit of BTX, the data were analysed separately by abduction deficit grade. Among seven patients with abduction deficit grade -4 , recovery was observed for four of four from the BTX group (100\%) and two of three from the conservative treatment group $(66.7 \%)$. Among 26 patients with grade -5 , recovery was observed for five of 10 from the BTX group (50\%) and three of 16 from the conservative treatment group (18.8\%, $P=0.09$ ).

\section{Discussion}

Although BTX does not alter the natural history of sixth nerve palsies caused by diabetes mellitus, microvascular diseases, or viral infection, ${ }^{6,7}$ it is still considered beneficial. Early BTX injection eliminates symptoms of diplopia, and improves the patient's quality of life while waiting for recovery. Unlike those benefiting from the high spontaneous recovery rate of microvascular or inflammatory lesions, patients with traumatic sixth nerve palsy, especially complete palsy, may have less chance of recovery. ${ }^{9-11}$ Therefore, BTX is more valuable if it is demonstrated to facilitate recovery of traumatic sixth nerve palsy. However, as previously stated, there is no agreement about the effect of BTX on traumatic sixth nerve palsy among previous studies. In 1985, Scott and $\mathrm{Kraft}^{1}$ treated 17 patients with lateral rectus palsy and found that, in acute stages, BTX could prevent medial rectus contracture and allow full recovery of lateral rectus. However, only a few of their cases were 
considered to be acute and traumatic. In other reports, which included mostly traumatic cases, a high percentage (71-87\% overall, $90 \%$ in unilateral cases) of patients recovered lateral rectus function after BTX injection during the acute stage. ${ }^{2,4,5}$ Compared with the control groups, in which $30 \%$ recovered spontaneously, this was a significant difference in recovery rate. ${ }^{2}$ Thus, it was concluded that BTX injection in acute traumatic sixth nerve palsy was beneficial and that BTX could facilitate lateral rectus function recovery, and play a useful role in the early management of traumatic sixth nerve palsy.

However, some reports had different results. Fitzsimons and coauthors conducted a retrospective study that enrolled 55 patients with sixth nerve palsy. Of these cases, $50 \%$ were traumatic and four were acute. This study concluded that BTX injection alone would not deliver a functional cure for traumatic sixth nerve palsy, and might only be useful as an adjunct to conventional management. ${ }^{6}$ In a prospective multicenter study carried out by Holmes et al, ${ }^{8}$ the recovery rate for acute traumatic sixth nerve palsy after early BTX injection was not different from that for conservative treatment (73 vs 71\%). These studies did not show any significant benefits to BTX treatment for acute sixth nerve palsy.

It is hard to draw a conclusion from any of these studies for several reasons. First, only a few of them represented purely traumatic sixth nerve palsy; most of them included multiple aetiologies. Palsies caused by other aetiologies had higher recovery rates, which caused the results to display it a tendency toward recovery in these reports that may not have been reliable. Second, the studies did not use a consistent definition for 'recovery'. Some authors used subjective criteria to define a recovery, such as 'complete abduction of the affected eye and absence of diplopia', ${ }^{11}$ or 'fusion in primary position', ${ }^{4}$ while others used more quantitative criteria like 'residual esophoria or esotropia $<5 \mathrm{PD}^{\prime},{ }^{6}$ or " $\leqslant 10 \mathrm{PD}$ distance esotropia in primary position'. ${ }^{8}$ Unrestrictive or subjective criteria, then, could have made the results more favourable with regard to the recovery rate. Conversely, strict criteria may have made the results more unfavourable, but more convincing. Third, unilateral palsies have a better chance of recovery than bilateral ones. ${ }^{9}$ Therefore, they should be analysed separately. Many studies put them together as a whole group, that affected the results. Finally, most important of all, previous reports did not confine their approach to a specific grade of severity. As the severity of palsy affects prognosis of the palsy significantly, ${ }^{9}$ it should always be taken into consideration when interpreting the data.

Furthermore, patients of a referral centre tend to be more severely injured, and have poorer prognoses. ${ }^{12}$ Theoretically, the referral groups have lower recovery rates than the nonreferral groups. This is also one of the reasons why there is a disparity in the different studies mentioned above. Despite the heterogeneous groups of patients in the previous literature, we only enrolled patients on a referral basis who had acute sixth nerve palsy that was unilateral complete palsy caused by trauma. In addition, we used a strict and quantitative definition for recovery. Avoiding the bias that previous studies might contain, we believe these criteria are more reliable in confirming the effect of BTX on acute traumatic sixth nerve palsy.

However, there are still potential biases to consider in the interpretation of our results. First, the time for assessment of recovery is hard to standardize. Since the assessment of outcome should be at least 3 months after the last injection of BTX to be sure of true recovery, the outcome was assessed later than 6 months in two patients with three injections, and in one patient with four injections. This bias could make the result of the BTX group more favourable. Incomplete follow-up might be a second source of bias. Two nonresolved patients receiving conservative treatment had less than 6 months of follow-up and were excluded. In addition, we performed further analyses assuming first that all excluded patients had recovered, and second that they had not recovered. This gave an estimate of a maximum recovery rate of $33.3 \%$ and a minimum recovery rate of $23.8 \%$ in the conservative treatment group. The recovery rate in the BTX group is still significantly higher than the estimated minimum recovery rate of the conservative treatment group $(P=0.006)$. We would lose the statistical power to demonstrate significant difference in recovery rate between the BTX group and the conservative treatment group if all the excluded patients did recover $(P=0.057)$, but there was still a trend that the BTX had more favourable result.

We have revealed a low spontaneous recovery rate (26.3\%) for unilateral complete sixth nerve palsy caused by trauma. Since most of our patients presented with grade -5 of abduction deficit, it is reasonable that our recovery rates are lower than the those described in previous studies (27-70\%), 2,11,12 in which most patients presented with grades -1 to -4 of abduction deficit. Based on a referral group of patients, the recovery rate in our study is also lower than in nonreferral groups of patients (70\% for unilateral complete palsy). ${ }^{12}$ The recovery rate in the BTX group was $64.3 \%$, which was significantly higher than in the conservative group. These rates demonstrated a beneficial effect of BTX in facilitating recovery of complete traumatic sixth nerve palsy. To further determine whether severity influenced the benefit of BTX, the data were analysed separately by abduction deficit grade. Among 26 patients with grade -5 abduction deficit, recovery rate was also higher in the BTX-treated patients than in the conservatively treated 
patients (50 vs $18.8 \%, P=0.09$ ), although the statistical power was low due to small sample size.

Conversely, the study carried out by Holmes et al ${ }^{8,9}$ showed the same high overall recovery rates between BTX group and conservative treatment group (73 vs $71 \%$ ). They also found that recovery rates in the subgroup of grade -5 abduction deficit were similar between BTX-treated patients and conservatively treated patients (38 vs 31\%). Thus, they claimed that there was no benefit to BTX treatment for acute traumatic sixth nerve palsy. It may be true that patients with minor injury and incomplete palsy do not benefit from BTX injection because of the native potential to recover. But patients with the most severe complete palsy, who are often seen in a referral center, are not likely to recover spontaneously, and BTX injection could play an important role in facilitating the recovery. It is possible that the Holmes study missed a BTX effect in the cases with abduction deficit of grade -5 due to the small sample size. Furthermore, they did not separate unilateral from bilateral cases in the subgroup of grade -5 , which could also make the results confusing. Even though BTXs effect on recovery rate has yet to be confirmed, it can be still beneficial. For example, in our nonrecovered or partially recovered patients, the BTX group had smaller final deviation than the conservative group. The subsequent surgery can thus be minimized and has a better chance of success. It is beyond doubt that BTX is a good adjunct to conventional management.

Complete traumatic sixth nerve palsies have much less favourable outcome than incomplete palsies. Among complete palsies, those with grade -5 abduction deficit (inability to abduct the eye to midline) have the worst prognosis. Since most of our patients presented with inability to abduct the eye to midline, our results are most applicable to those cases. Although our study is limited by our small numbers and by the fact that it is retrospective and nonrandomized, the results are still encouraging and inspiring. Since patients with severe head injury and complete sixth nerve palsy often suffer from nonrecovery, we should treat them more aggressively. BTX is a choice for providing immediately symptomatic relief and long-term therapeutic success.

\section{References}

1 Scott AB, Kraft SP. Botulinum toxin injection in the management of lateral rectus paresis. Ophthalmology 1985; 92: 676-683.

2 Metz HS, Mazow M. Botulinum toxin treatment of acute sixth and third nerve palsy. Graefes Arch Clin Exp Ophthalmol 1988; 226: 141-144.

3 Wagner RS, Frohman LP. Long-term results: botulinum for sixth nerve palsy. J Pediatr Ophthalmol Strabismus 1989; 26: 106-108.

4 Murray ADN. Early and late botulinum toxin treatment of acute sixth nerve palsy. Aust NZ J Ophthalmol 1989; 17: 239-245.

5 Metz HS, Dickey CF. Treatment of unilateral acute sixthnerve palsy with botulinum toxin. Am J Ophthalmol 1991; 112: $381-384$.

6 Fitzsimons R, Lee J, Elston J. The role of botulinum toxin in the management of sixth nerve palsy. Eye 1989; 3: 391-400.

7 Lee J, Harris S, Cohen J, Cooper K, MacEwen C, Jones S. Results of a prospective randomized trial of botulinum toxin therapy in acute unilateral sixth nerve palsy. J Pediatr Ophthalmol Strabismus 1994; 31: 283-286.

8 Holmes JM, Beck RW, Kip KE, Droste PJ, Leske DA, PEDIG. Botulinum toxin treatment versus conservative management in acute traumatic sixth nerve palsy or paresis. JAAPOS 2000; 4 : 145-149.

9 Holmes JM, Beck RW, Kip KE, Droste PJ, Leske DA, PEDIG. Predictors of nonrecovery in acute traumatic sixth nerve palsy and paresis. Ophthalmology 2001; 108: 1457-1460.

10 Rush JA, Younge BR. Paralysis of cranial nerves 3, 4, and 6: cause and prognosis in 1,000 cases. Arch Ophthalmol 1981; 99: 76-79.

11 Mutyala S, Holmes JM, Hodge DO, Younge BR. Spontaneous recovery rate in traumatic sixth-nerve palsy. Am J Ophthalmol 1996; 122: 898-899.

12 Holmes JM, Droste PJ, Beck RW. The natural history of acute traumatic sixth nerve palsy or paresis. JAAPOS 1998; 2 : 265-268. 